\title{
Toward unraveling the complexity of simple epithelial keratins in human disease
}

\author{
M. Bishr Omary, ${ }^{1}$ Nam-On Ku, ${ }^{1,2}$ Pavel Strnad, ${ }^{3}$ and Shinichiro Hanada ${ }^{1,4}$
}

\begin{abstract}
1Department of Molecular \& Integrative Physiology, University of Michigan Medical School, Ann Arbor, Michigan, USA. ${ }^{2}$ Department of Biomedical Sciences, Graduate School, Yonsei University, Seoul, Republic of Korea. ${ }^{3}$ Department of Internal Medicine I, University Medical Center UIm, Ulm, Germany. ${ }^{4}$ Division of Gastroenterology, Department of Medicine, Kurume University School of Medicine, Kurume, Japan.
\end{abstract}

\begin{abstract}
Simple epithelial keratins (SEKs) are found primarily in single-layered simple epithelia and include keratin 7 (K7), K8, K18-K20, and K23. Genetically engineered mice that lack SEKs or overexpress mutant SEKs have helped illuminate several keratin functions and served as important disease models. Insight into the contribution of SEKs to human disease has indicated that $\mathrm{K} 8$ and $\mathrm{K} 18$ are the major constituents of Mallory-Denk bodies, hepatic inclusions associated with several liver diseases, and are essential for inclusion formation. Furthermore, mutations in the genes encoding K8, K18, and K19 predispose individuals to a variety of liver diseases. Hence, as we discuss here, the SEK cytoskeleton is involved in the orchestration of several important cellular functions and contributes to the pathogenesis of human liver disease.
\end{abstract}

\section{Introducing keratins}

Intermediate filament (IF) proteins are the building blocks of cytoskeletal filaments with an average diameter greater than that of microfilaments and less than that of microtubules. IF proteins are expressed in a tissue- and cell compartment-specific manner $(1,2)$ and are subdivided into 5 major types based on similarities in amino acid sequence and protein structure. Types I-IV form cytoplasmic IFs, whereas type V IF proteins, the lamins, generate nuclear IFs. Keratins are the largest subgroup of IF proteins and are classified as type I and type II IF proteins (the acidic and basic keratins, respectively). Examples of type III IFs include desmin in muscle and vimentin in mesenchymal cells, and type IV IFs include neurofilament proteins of neuronal cells. Recently, a comprehensive nomenclature scheme was developed for keratins (3) that is increasingly being adopted. Briefly, the 54 functional human keratins are categorized according to the cells in which they are expressed (specifically, they are classified as epithelial keratins, encoded by 37 genes, and hair keratins, encoded by 17 genes) and are allocated a number; for example, type I epithelial keratins are numbered 9-28 and type II epithelial keratins are numbered 1-8 and 71-80 (3).

Several features distinguish keratins from other IF proteins (4): first, they are preferentially expressed in epithelial cells; and second, they are obligate noncovalent heteropolymers that include at least one type I and one type II keratin (Figure 1A). However, the structural organization of keratins is similar to all other IF proteins; they consist of a central coil-coil $\alpha$-helical rod domain that is flanked by non- $\alpha$-helical head and tail domains (5). The flanking domains contain most of the motifs for regulatory modification, including phosphorylation and glycosylation (Figure 1A), and impart most of the structural heterogeneity among different keratins (4). Furthermore, similar to other IFs, keratins exist in their simplest cytosolic form (6) as tetramers that include 2 heteropolymeric type I and type II dimers $(5,7)$.

Conflict of interest: The authors have declared that no conflict of interest exists. Nonstandard abbreviations used: CYFRA, cytokeratin fragment; DDC, 3,5-diethoxycarbonyl-1,4-dihydrocollidine; IBD, inflammatory bowel disease; IF, intermediate filament; K, keratin; MDB, Mallory-Denk body; SEK, simple epithelial keratin; TPA, tissue polypeptide antigen; TPS, tissue polypeptide-specific antigen. Citation for this article: J. Clin. Invest. 119:1794-1805 (2009). doi:10.1172/JCI37762.
An important feature of keratins is that specific keratin pairs predominate in an epithelial cell- and differentiation state-selective manner $(4,8)$. For example, epidermal basal keratinocytes express the keratin pair keratin 5/keratin 14 (K5/K14), whereas suprabasal keratinocytes express $\mathrm{K} 1 / \mathrm{K} 10$. The keratins that are predominantly expressed in simple (single-layered) epithelia are known as simple epithelial keratins (SEKs) and consist of K7, K8, $\mathrm{K} 18, \mathrm{~K} 19, \mathrm{~K} 20$, and $\mathrm{K} 23$. However, there is some promiscuity in SEK expression, as some SEKs are also found in tissues containing stratified epithelia (e.g., K7 and K19 in bladder epithelia), and some SEKs are expressed in nonepithelial tissues (e.g., K8 and K19 are expressed at low levels in muscle). In addition, as simple epithelia are commonly found lining glands and in organs involved in secretion and absorption, the individual cells are often polarized, which suggests that the unique expression of SEKs in these cells is likely to have functional consequences related to polarized protein sorting, absorption, and secretion $(9,10)$.

Mutations in the genes encoding IF proteins either directly cause or predispose their carriers to more than 80 human diseases (see ref. 11 and the Human Intermediate Filament Database; http://www.interfil.org/index.php). As the simple epithelia that express SEKs are a component of many tissues and organs, SEKs can potentially be involved in diseases affecting several organs (Figure 1B). To date, the liver appears to be the primary target organ, with mutations in the genes KRT8, KRT18, and $K R T 19$, which encode K8, K18, and K19, respectively, serving as factors that predispose individuals to liver disease (Figure 1B). In contrast, no human disease-associated mutations in KRT7, KRT20, and KRT23 have been reported thus far. SEKs also have disease relevance in other contexts: they are important in the formation of hepatocyte Mallory-Denk bodies (MDBs), which are hepatic inclusions observed in diverse chronic liver diseases; they serve as markers of some epithelial cancers; they are targets of autoantibodies; and they serve as markers of apoptosis. They are also important in protecting cells from undergoing apoptosis. Several recent reviews have covered K8 and K18 in the context of liver disease $(12,13)$ and IF proteins, including SEKs, in digestive organs (2). Thus, here we focus on SEKs K7, K8, $\mathrm{K} 18-\mathrm{K} 20$, and K23, highlighting their importance from disease and functional perspectives. 
A

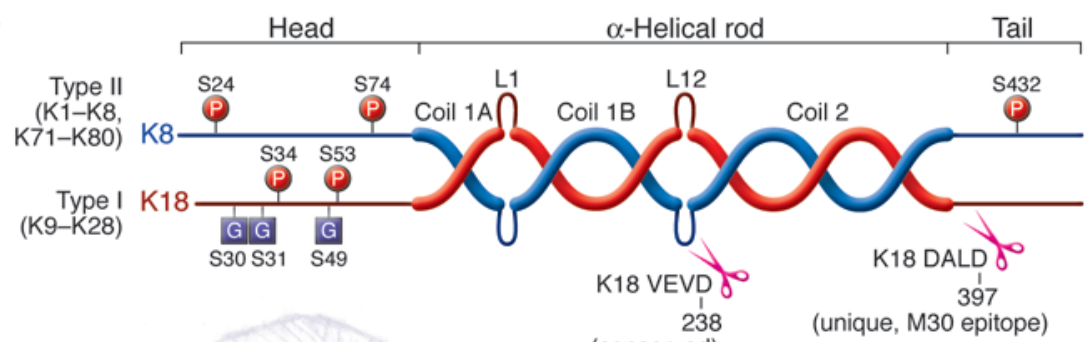

B

(conserved)

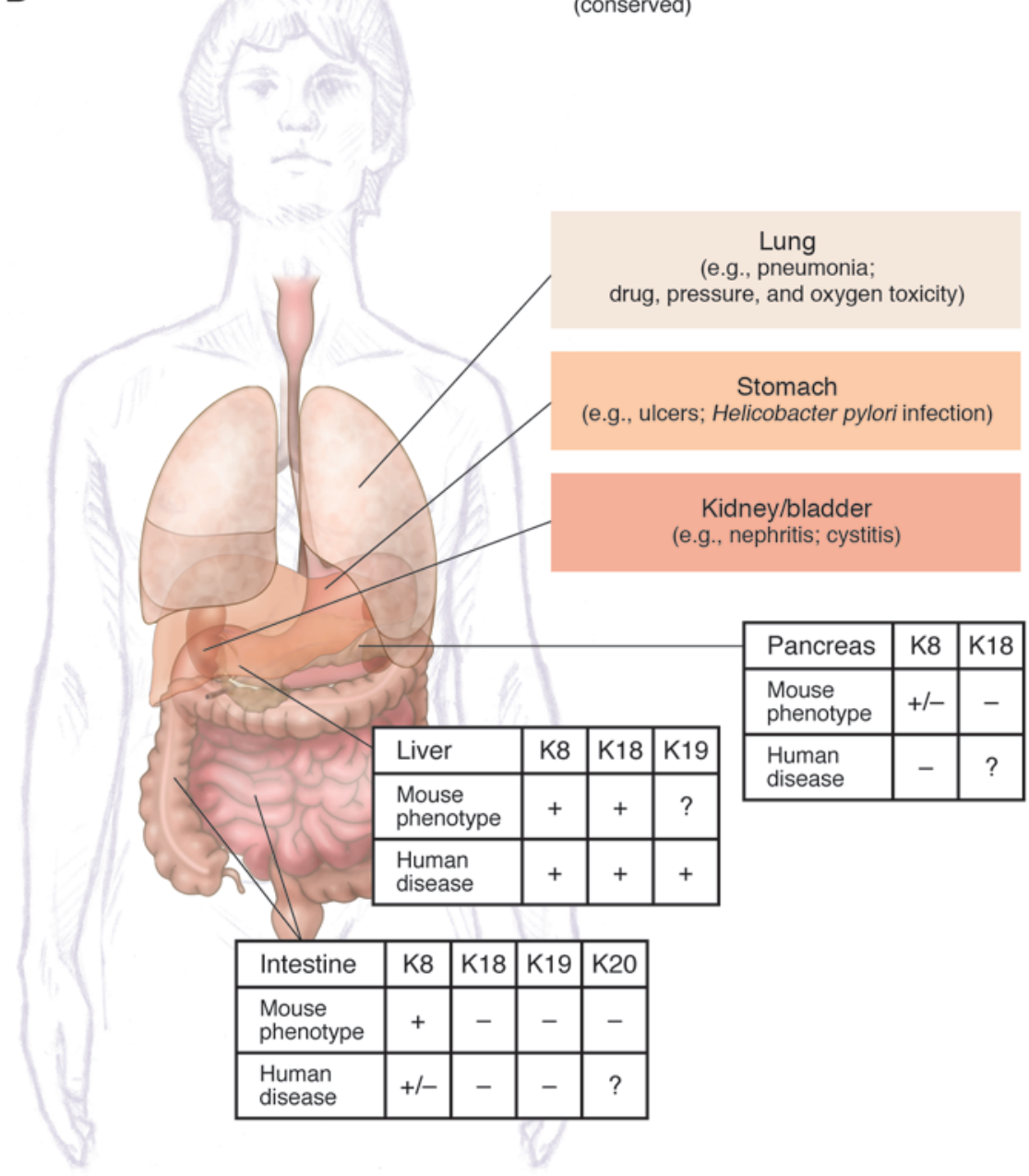

\section{Figure 1}

Keratin prototype structure and SEK-related diseases. (A) Keratins form obligate heteropolymers (one type I and one type II keratin) and share a common structure that consists of a central coiled-coil $\alpha$-helical rod domain that is flanked by non- $\alpha$-helical head and tail domains. The head and tail domains are unique in that they include most of the sites for posttranslational modifications [phosphorylation $(P)$ and glycosylation $(G)$ ]. The rod domain is subdivided into 3 subdomains (coils 1A, 1B, and 2) and by 2 linkers (L1 and $L 12)$. The $L 12$ region includes a highly conserved caspase-digestion site (VEVD in K18) among type I keratins and other IFs, while only the K18 tail domain has a caspase cut site (DALD). The K18 VEVD and DALD (the M30 epitope) are recognized by epitopespecific antibodies $(40,41,54)$. (B) Liver, pancreas, and intestine phenotypes caused by keratin mutations, as determined from findings in SEK-related animal models or in human patient studies. +, positive phenotype; -, absent phenotype; +/-, borderline phenotype; ?, untested and therefore unknown. Borderline phenotypes were assigned in the case of $\mathrm{K} 8$ mouse pancreas because pancreatitis develops after $\mathrm{K} 8$ overexpression, but at high gene copy numbers, and in the case of human intestine because $\mathrm{K} 8 / \mathrm{K} 18$ variants are unlikely to be involved in predisposition to IBD. Also shown are some of the organs that we hypothesize may ultimately prove to be involved in additional SEK variant-associated human diseases, with a few potential candidates listed.

\section{Expression and regulation of SEKs in normal and stressed tissues}

On a tissue basis, the most abundant and most studied SEKs are K8 and K18 (14). Many simple epithelia also express variable levels of $\mathrm{K} 7, \mathrm{~K} 19$, and $\mathrm{K} 20$, although adult hepatocytes and proximal renal tubular epithelial cells (both of which are polarized simple epithelial cells) express K8 and K18 exclusively (Table 1 and refs. 12, 15). In contrast, enterocytes manifest a complex distribution that depends on the differentiation state and specific cell type (Table 1). Limited information is available regarding the more recently identified K23, but we include it among the SEKs because it is expressed in pancreatic and colonic tumors (Table 1), albeit at very low levels (16-18).

K8 and K18 are also found in pseudostratified and urothelial epithelia, where they are expressed mainly in luminal cells. K7 and K19 serve as markers of ductal epithelia and are also found in gastrointestinal epithelia, whereas minor levels of K18 and K19 are occasionally present in the basal layer of nonkeratinizing stratified squamous epithelia (15). K20 is found primarily in terminally differentiated enterocytes, urothelial and gastric epithelia, and neuroendocrine cells, including Merkel cells of the skin (15); it is also markedly upregulated, together with K8, K18, and K19, upon pancreatic injury (19).

Some cell types exhibit a polarized distribution of SEKs within distinct subcellular compartments, as noted in pancreatic mouse acinar cells. For example, K8 and K18 localize preferentially within cytoplasmic filaments, whereas K7 and K19 are found primarily in the membrane-proximal apicolateral compartment (20). This distinct subcellular localization may reflect the different keratin assembly properties that are observed when the proteins are examined in their purified forms or upon cell transfection (21), or may 
Table 1

SEK distribution in normal and neoplastic tissues

\begin{tabular}{|c|c|c|}
\hline Tissue & Keratin expression & Refs. \\
\hline \multicolumn{3}{|l|}{ Non-neoplastic } \\
\hline Axillary gland (acini) & K4, K5, K7, K8, K14, K19 (K13, K17, K18) & (8) \\
\hline Eccrine sweat gland (total) & K5, K6, K7, K8, K14, K15, K18, K19 (K17) & (8) \\
\hline Mammary gland-ducts & $\mathrm{K} 5, \mathrm{~K} 7, \mathrm{~K} 8, \mathrm{~K} 14, \mathrm{~K} 17, \mathrm{~K} 19$ (K15, K18) & (8) \\
\hline Tracheal epithelium & K5, K8, K13, K15, K17, K19 (K6, K7, K14, K18) & (8) \\
\hline Amnion epithelium & K5, K6, K8, K17, K19 (K14, K18) & (8) \\
\hline Transitional epithelium-bladder & $\mathrm{K} 7, \mathrm{~K} 8, \mathrm{~K} 19$ (K5, K13, K18, K20) & (8) \\
\hline Gallbladder epithelium & K8, K18 (K7, K19, K20) & $(2,29)$ \\
\hline Stomach & $\mathrm{K} 8, \mathrm{~K} 18, \mathrm{~K} 19, \mathrm{~K} 20$ (K7) & (2) \\
\hline Small intestine (mucosa) ${ }^{\mathrm{A}}$ & K8, K18, K19, K20 (K7) & (2) \\
\hline Colon (mucosa) ${ }^{\mathrm{A}}$ & K8, K18, K19, K20 (K7) & $(2,8)$ \\
\hline Hepatocyte (adult) & K8, K18 & (23) \\
\hline Cholangiocytec ${ }^{\mathrm{C}}$ & K7, K8, K18, K19 & (23) \\
\hline Stem (oval) cells $\mathrm{S}^{\mathrm{D}}$ & $\mathrm{K} 7, \mathrm{~K} 8, \mathrm{~K} 18, \mathrm{~K} 19$ & (23) \\
\hline Pancreas-acinare & $\mathrm{K} 8, \mathrm{~K} 18, \mathrm{~K} 19$ & (2) \\
\hline Ductal pancreas & $\mathrm{K} 8, \mathrm{~K} 19(\mathrm{~K} 7, \mathrm{~K} 18)$ & (2) \\
\hline Kidney-tubuliF & K8, K18 & (24) \\
\hline Kidney-limbs of Henle & K7, K8, K18, K19 & (24) \\
\hline Kidney-collecting duct ${ }^{G}$ & $\mathrm{~K} 8, \mathrm{~K} 18(\mathrm{~K} 7, \mathrm{~K} 19)$ & (24) \\
\hline \multicolumn{3}{|l|}{ Neoplastic } \\
\hline Hepatocellular carcinoma & K8, K18 (K7, K19, K20) & (15) \\
\hline Colon adenocarcinoma & K8, K18, K19, K20 (K7, K23) & $(15,17)$ \\
\hline denocarcinoma & $\mathrm{K} 8, \mathrm{~K} 18, \mathrm{~K}$ & (15) \\
\hline Esophagus adenocarcinoma ${ }^{H}$ & K7, K8, K18, K19 (K20) & (33) \\
\hline Pancreas adenocarcinoma & K7, K8, K18, K19 (K5, K14, K15, K16, K17, K20) & (33) \\
\hline Lung adenocarcinoma & $\mathrm{K} 7, \mathrm{~K} 8, \mathrm{~K} 18, \mathrm{~K} 19$ (K12, K14, K17) & $(15,33)$ \\
\hline Lung small cell & $\mathrm{K} 8, \mathrm{~K} 18, \mathrm{~K} 19(\mathrm{~K} 7)$ & $(15,33)$ \\
\hline Ovary adenocarcinoma & K7, K8, K18, K19 (K5, K6, K20) & $(15,33)$ \\
\hline Renal cell, clear cell & K8, K18 (K19) & (15) \\
\hline Renal cell, papillary & $\mathrm{K} 7, \mathrm{~K} 8, \mathrm{~K} 18, \mathrm{~K} 19$ & (15) \\
\hline Renal cell, chromophobe & K7, K8, K18 (K19) & $(15)$ \\
\hline Malignant mesothelioma & K5, K6, K8, K12, K17, K18, K19 (K7, K14) & $(15,33)$ \\
\hline Merkel cell carcinoma & K8, K18, K19, K20 (K7) & $(15,33)$ \\
\hline Breast adenocarcinoma & $\mathrm{K} 7, \mathrm{~K} 8, \mathrm{~K} 18, \mathrm{~K} 19$ (K4, K5, K6, K14, K17) & $(15,33)$ \\
\hline Endometrial adenocarcinoma & $\mathrm{K} 7, \mathrm{~K} 8, \mathrm{~K} 18, \mathrm{~K} 19$ (K5, K6, K14) & $(15,33)$ \\
\hline Transitional cell-bladder & $\mathrm{K} 4, \mathrm{~K} 5, \mathrm{~K} 6, \mathrm{~K} 7, \mathrm{~K} 8, \mathrm{~K} 17, \mathrm{~K} 18, \mathrm{~K} 19$ (K14, K20) & (33) \\
\hline Thyroid papillary & $\mathrm{K} 7, \mathrm{~K} 8, \mathrm{~K} 18$ (K5, K6, K13, K19) & (33) \\
\hline
\end{tabular}

Keratins in parentheses are expressed at lower levels or found only in a subset of tumors. AWithin enterocytes, $\mathrm{K} 7$ is expressed mainly in the proliferating cell compartment at the crypt base, while $\mathrm{K} 20$ is found in the differentiated cell population adjacent to the villus tip. In mouse small intestine, K18 is preferentially located in the crypts, and nearly exclusively in the goblet cells suprabasally, while it is distributed broadly throughout the crypt-villus axis in the colon $(2,80)$. KRT23 mRNA has been detected in normal human colon and other tissue, including skin, tongue, breast, placenta, eye, pancreas and lung (18). At the protein level, K23 protein is detected in a pancreatic tumor cell line only after culturing in the presence of butyrate (16) and in fresh human colon cancers but not in normal colon (17). ${ }^{\text {BAlso }}$ K19 during embryogenesis. CAlso K20 in rat. DAlso K14 in rat. EK19 is distributed only in the apicolateral compartment under basal conditions (20). ${ }^{\mathrm{F}}$ Also minimal levels of $\mathrm{K} 7$ and $\mathrm{K} 19$, and vimentin in convoluted part of proximal tubule. ${ }^{\mathrm{G}} \mathrm{Als}$ m minimal levels of $\mathrm{K} 4, \mathrm{~K} 5, \mathrm{~K} 13$, and $\mathrm{K} 17$ in medulla. ${ }^{\mathrm{H}} \mathrm{K} 7$ and $\mathrm{K} 20$ staining may also be useful for distinguishing between the potentially precancerous Barrett's esophagus metaplasia and gastric cardia intestinal metaplasia, but the studies are somewhat conflicting based on a systematic review of published literature (125). and manifest a highly dynamic expression profile during embryogenesis and in some stress conditions. During embryogenesis, expression of type II keratins precedes expression of type I keratins, although members of both families are needed to form typical cytoplasmic filaments (22). Furthermore, fetal hepatoblasts express $\mathrm{K} 7, \mathrm{~K} 14$, and K19, none of which are detected in adult hepatocytes (23). In fetal kidney, keratins and vimentin are often coexpressed, whereas they are rarely found within the same cell in adults (24). Similar to embryogenesis-related changes, stress-induced changes in keratin expression are probably caused by regeneration-associated deor transdifferentiation. For example, de novo K7 and, to a lesser extent, K19 expression is found in human cholestatic liver disorders and after excessive alcohol damage $(12,25)$. In chronic kidney damage, increased or de novo expression of K7, K17, and K19 as well as other nonkeratin IFs has been observed (24).

Stress conditions affect not only keratin expression profiles, but also keratin expression levels and posttranslational modification. For example, increased keratin phosphorylation is a marker of tissue injury and disease progression in human and mouse liver (12) and in mouse intestinal goblet cells (26). Under certain stress conditions, expression of SEKs increases up to 3 -fold, which may contribute to the essential cytoprotection provided by $\mathrm{K} 8$ and K18 in the liver, although the importance of such upregulation has not been directly demonstrated (12). SEK overexpression after injury has been noted in mouse liver $(27,28)$ and in experimental mouse pancreatitis (19) and cholelithiasis (29). These findings in rodents are supported by the observation of $\mathrm{K} 8$ and $\mathrm{K} 18$ induction in patients with primary biliary cirrhosis (PBC; ref. 30). Alternatively, stress can also promote K8 and K18 degradation, as noted in cultured human A549 cells exposed to shear stress (31), but it is not clear if this also occurs in vivo and whether keratin induction versus degradation differs depending on the injury or involved tissue. For example, K8, K18, and K19 are exceptionally resistant to degradation during experimental pancreatitis, whereas actin and tubulin undergo dramatic proteolysis (32). These observations provide a clear distinction between SEKs and the microfilament and microtubule cytoskeleton in terms of their response to injury. reflect unique keratin modifications or associated protein interactions. Notably, K19 and K20 upregulation upon pancreatic injury is accompanied by their incorporation into cytoplasmic filaments, although this localization reverts to the typical apicolateral distribution upon healing (19).

As part of their diversity in numbers, structure, and tissue-specific expression, keratins serve as important histological markers

\section{SEK expression in epithelial tumors, and the role of SEKs as tumor and metastasis markers}

The expression of multiple SEKs in an epithelial cell-specific manner and the fact that keratin expression profiles remain relatively stable during neoplastic transformation (although levels may decrease substantially, or new keratin/IF expression may occur) explains why keratins are commonly used tumor markers. For 
example, staining with a pan keratin-specific antibody distinguishes epithelial from nonepithelial tumors, and this approach is used extensively in pathology laboratories worldwide. Furthermore, characterization of the precise keratin expression pattern allows prediction of the origin of the primary tumor when assessing metastases (15): hepatocellular carcinomas typically expresses $\mathrm{K} 8$ and $\mathrm{K} 18$, and cholangiocarcinomas express $\mathrm{K} 7$ in addition to $\mathrm{K} 8$ and $\mathrm{K} 18$, while metastases of colorectal carcinomas express $\mathrm{K} 20$, but not $\mathrm{K} 7(15,33,34)$.

SEKs are the major keratin species in tumors arising from simple (including mesothelioma) and transitional epithelia and are either absent or expressed at low levels in basal cell carcinomas, myoepitheliomas, and squamous cell carcinomas (Table 1 and ref. 33). Other tumors that retain the SEK expression pattern indicative of their cell of origin include a subset of gastric adenocarcinomas and Merkel cell carcinoma of the skin $(15,33)$. In the kidney, keratin expression discriminates between conventional renal cell carcinoma (which lacks both K7 and K20), papillary carcinoma (which expresses both K7 and K19), and chromophobe carcinoma (which expresses K7, but typically little K19; refs. 15, 33). In the lung, adenocarcinomas originating from alveolar cells express $\mathrm{K} 7$ and K18, whereas squamous cell carcinomas stemming from bronchial epithelia express K10 and K13, but not K7 or K18 (33). Also, both keratin expression profile and keratin distribution are important. For example, ductal breast carcinomas display a peripheral K8 staining pattern, whereas lobular breast carcinomas exhibit a ring-like perinuclear K8 distribution (35). In addition, assessing the expression of SEKs, non-SEKs, and other IF proteins can be diagnostically beneficial. For example, the presence of SEKs together with stratified keratins is characteristic of transitional cell carcinoma - the most common form of bladder cancer - and malignant mesothelioma, and expression of vimentin and keratins is seen in conventional renal cell carcinoma and malignant mesothelioma $(15,33)$.

The keratin expression pattern can also be useful in predicting tumor prognosis. In colorectal carcinoma, low K20 expression is seen in carcinomas with high microsatellite instability, which constitute a distinct $15 \%$ entity of colorectal cancers and are associated with improved survival compared with colorectal carcinomas with low microsatellite instability (36). In breast cancer, expression of $\mathrm{K} 8$ and $\mathrm{K} 18$ is associated with favorable outcome, whereas the occurrence of K5, K14, and K17 carries a poor prognosis $(15,33)$. In the normal bladder, $\mathrm{K} 20$ is confined to the superficial umbrella cells, and in noninvasive transitional cell carcinoma, the persistence of this expression pattern predicts that the tumor is unlikely to recur (15).

Beyond the role of keratins as markers of epithelial tumors and metastasis, several reports suggest a direct beneficial impact of K18 in breast cancers. For example, K18 is downregulated in advanced and high-grade tumors, and its suppression is associated with shorter patient survival (37). Similarly, K18 overexpression in a breast cancer cell line led to reduced invasiveness of the cells in vitro and to reduced tumorigenicity in nude mice (38). Although additional studies are needed, it appears that SEK expression levels may positively correlate with lower tumor invasiveness.

\section{SEKs as serum markers of tissue injury, epithelial cancers, and treatment response}

SEKs or SEK fragments circulating in serum, which are released from apoptotic or necrotic tumor and nontumor cells, have been used as tumor markers for monitoring disease progression in sev- eral cancers (39). The most commonly used markers are tissue polypeptide antigen (TPA; a mixture of K8, K18, and K19), tissue polypeptide-specific antigen (TPS; derived from K18), cytokeratin fragment 21-1 (CYFRA 21-1; derived from K19), and a caspasegenerated fragment of K18 that contains the neoepitope Asp397 recognized by the antibody M30 $(40,41)$. TPA has been used as a potential serum marker to identify individuals with various epithelial cell-associated carcinomas, including those involving breast, colorectum, lung, and bladder (42). TPS and CYFRA 21-1 have been used clinically in the care of individuals with cancers of the breast, ovary, prostate, and lung. The main potential clinical uses of TPA, TPS, and CYFRA 21-1 are to monitor treatment responses and tumor recurrence and to provide prognostic information. For example, in breast cancer, a rapid decrease in TPS levels after the initiation of therapy has been suggested to signify an effective response, whereas increased or unchanged levels indicate an inadequate response, but the recommendation for its routine use as a tumor marker differs among clinical organizations (43). Similar findings have been reported for TPA, TPS, and CYFRA in nonsmall cell lung cancers (44). However, these markers have somewhat limited clinical utility because of their lack of organ specificity and elevated serum levels in some nonmalignant diseases; for example, high CYFRA levels accompany interstitial pulmonary fibrosis (45), and high TPS levels are found in the context of several liver disorders (46). Additional data are needed to establish the clinical utility of serum SEK measurements in malignant disorders and the relative potential interference from nonmalignant diseases.

Another SEK-related marker is the M30 epitope (Figure 1A), which is a promising probe for detecting caspase activation in several clinical contexts. For example, it has been detected in the sera of patients infected with $\mathrm{HCV}$, where it is a marker of fibrotic liver injury (47); used to predict who may respond to anti-HCV therapy (48); applied as a potential noninvasive correlate of the histological severity in nonalcoholic steatohepatitis (49); and used as a potential marker for monitoring the state of liver injury associated with chronic infection with HBV (50). Furthermore, the presence of $\mathrm{M} 30$ reactivity in the serum may prove useful in distinguishing liver and intestinal graft-versus-host disease from unrelated conditions with similar symptoms (51). However, additional studies are needed to test larger numbers of patients and appropriate clinical controls, to analyze different sources of samples (serum versus plasma) and handling conditions (52), and to make the distinction between fragments generated by apoptosis and necrosis (53). As K18 undergoes 2 sequential caspase cleavages (Figure 1A), determining the circulating levels of the exposed epitope corresponding to the second K18 caspase cleavage site (54), as well as K19 (54) and K20 (26) apoptotic fragments, may provide added benefit.

\section{SEK expression in nonepithelial tissues in normal and disease states}

In addition to their prototypical tissue-specific and differentiation-dependent expression, SEKs are also detected in some nonepithelial contexts. For example, K8 and K19 are expressed in adult cardiac muscle, where they are localized at the Z-disks and M-lines of myofibrils near the sarcolemma, while K18 expression in the heart is restricted in embryos up to day 16 and disappears in adults (55). The importance of K19 expression in muscle is magnified in K19-deficient mice, which develop a mild myopathy of fast-twitch skeletal muscle in association with costamere disruption and mitochondria accumulation in gaps between the sarcolemma and 
Table 2

Transgenic animal models of SEK

\begin{tabular}{|c|c|c|c|}
\hline Keratin & Mouse model & notype & Refs. \\
\hline K7 & None described & - & - \\
\hline K8 & Knockout (in C57BI/6) & Liver hemorrhage with embryo lethality & $(64)$ \\
\hline K8 & Knockout (in FVB/n) & Colorectal hyperplasia; colitis and mild hepatitis & $(65)$ \\
\hline K8 & Mouse WT overexpression & $\begin{array}{l}\text { Spontaneous MDB formation; chronic pancreatitis } \\
\text { only when expression levels are very high }\end{array}$ & $(79,126)$ \\
\hline K8 & Human WT with high overexpression & Chronic pancreatitis & (78) \\
\hline K8 & Human G62C (a human-related genetic variant) & $\begin{array}{l}\text { Predisposition to liver injury and apoptosis; inhibition } \\
\text { of K8 S74 phosphorylation by stress kinases }\end{array}$ & $(70)$ \\
\hline K8 & Human S74A (prevents S74 phosphorylation) & Predisposition to liver injury and apoptosis & (70) \\
\hline K8 & Human R341H (a human-related genetic variant) & Predisposition to liver injury & PS and MBO \\
\hline K18 & Knockout & $\begin{array}{l}\text { Spontaneous MDB formation, mild hepatitis, } \\
\text { and increased hepatocyte fragility }\end{array}$ & $(69,70)$ \\
\hline K18 & Human WT overexpression & Resistant to MDB formation, otherwise normal & $(127)$ \\
\hline K18 & $\begin{array}{l}\text { Human R90C overexpression } \\
\text { (mutation hot spot in other keratins) }\end{array}$ & $\begin{array}{l}\text { Mild hepatitis; hepatocyte fragility; marked predisposition } \\
\text { to liver injury; liver and pancreas keratin filament disruption }\end{array}$ & $(72,73)$ \\
\hline K18 & $\begin{array}{l}\text { Human S34A overexpression } \\
\text { (prevents S34 phosphorylation and 14-3-3 binding) }\end{array}$ & $\begin{array}{l}\text { Abnormal mitotic bodies after partial hepatectomy; } \\
\text { persistent 14-3-3 nuclear localization }\end{array}$ & $(83)$ \\
\hline K18 & $\begin{array}{l}\text { Human S53A overexpression } \\
\text { (prevents S53 phosphorylation) }\end{array}$ & Predisposition to liver injury & $(82)$ \\
\hline K19 & Knockout & $\begin{array}{l}\text { Compensatory K18 and K20 overexpression in gallbladder; } \\
\text { mild myopathy }\end{array}$ & $(29,56)$ \\
\hline K19 & Human WT overexpression & None & $(128)$ \\
\hline K20 & Human WT overexpression & $\begin{array}{l}\text { Lack of K20 distribution in pancreas and stomach } \\
\text { (related to the genomic transgene used) }\end{array}$ & $(80)$ \\
\hline K20 & Human R80H overexpression & Disruption of keratin filaments in small intestine enterocytes & $(80)$ \\
\hline K8, K19 & Double knockout & Degeneration of placenta with embryo lethality & $(129)$ \\
\hline K18, K19 & Double knockout & Fragility of trophoblast giant cells with embryo lethality & $(130)$ \\
\hline K18, K19 & Mixed K19 knockout and K18 dominant negative & $\begin{array}{l}\text { Lethal at E10.5 when K18 is null on one copy and mutant R90C on the } \\
\text { other, which is rescued when the null K18 is replaced with a WT copy }\end{array}$ & (131) \\
\hline
\end{tabular}

PS and MBO, P. Strnad and M.B. Omary, unpublished observations.

adjacent myofibrils (56). Based on these findings, it is relevant to examine the muscle phenotype in K8-deficient mice.

The corneal endothelium, a monolayer of flat hexagonal cells, also expresses the K8/K18 pair. Furthermore, the abnormal corneal endothelium in patients with posterior polymorphous corneal dystrophy (PPCD) manifests multilayered features with expression of predominantly K7 and K19 in addition to K8 and K18 $(57,58)$. This altered keratin expression may reflect a metaplastic process that entails a shift of endothelial to epithelial phenotypes.

Ectopic keratin expression also occurs during atherosclerosis of coronary artery disease. In this setting, VSMCs in atherosclerotic lesions express $\mathrm{K} 8 / \mathrm{K} 18$, which is not detectable in normal vessels (59). Keratin expression in these cells requires both cellular attachment to extracellular matrix proteins and mitogenic stimulation (60). The induced K8/K18 are hyperphosphorylated because of a stress response, which is seen as a typical IF injury response (61), or possibly as a result of apoptosis during atherosclerotic plaque maturation, which leads to fibrosis (62). Notably, VSMCs of human umbilical cord vessels express K8, K18, and K19 $(62,63)$, which may be compatible with myogenic differentiation (63).

\section{SEK-related diseases and functions highlighted by transgenic animal models}

The generation of SEK knockout and transgenic mice has provided essential information regarding keratin function in vivo and has guided the identification of candidate human diseases that are related to mutations in genes encoding SEKs (12). K7 and K23 are the only SEKs for which animal models have not been described (Table 2). K8-deficient C57BL/6 mice, which exhibited liver hemorrhage and greater than $90 \%$ embryo lethality (64), were the first IF protein-deficient mice generated. Backcrossing the few K8-deficient survivors onto an FVB background generated mice with $50 \%$ embryo lethality; although the surviving mice had a normal life span, they exhibited an ulcerative colitis-like phenotype (65-67) and substantial hepatocyte fragility and susceptibility to liver injury (68). Although both K8- and K18-deficient mice lack hepatocyte keratin filaments, their phenotype (albeit on different genetic backgrounds) is partially different. For example, no embryo lethality or colitis is observed in K18-deficient mixed-background mice because of functional redundancy with K19 (69), but both K8-null and K18-null mice have increased hepatocyte fragility $(68,70)$ and susceptibility to hepatocyte apoptosis $(41,71)$. The first clear and detailed link between SEKs and liver disease came from mice that overexpressed the R90C mutant of K18; these mice exhibited mild chronic hepatitis and marked hepatocyte fragility upon liver perfusion (72), with dramatic susceptibility to liver injury (73). It was this observation that led to the testing and initial identification of mutations in KRT18 (74) and then KRT8 (75) in patients with liver disease.

The liver is the primary organ affected by KRT8 and KRT18 mutations, although K8 and K18 are found in several secretory tissues, 


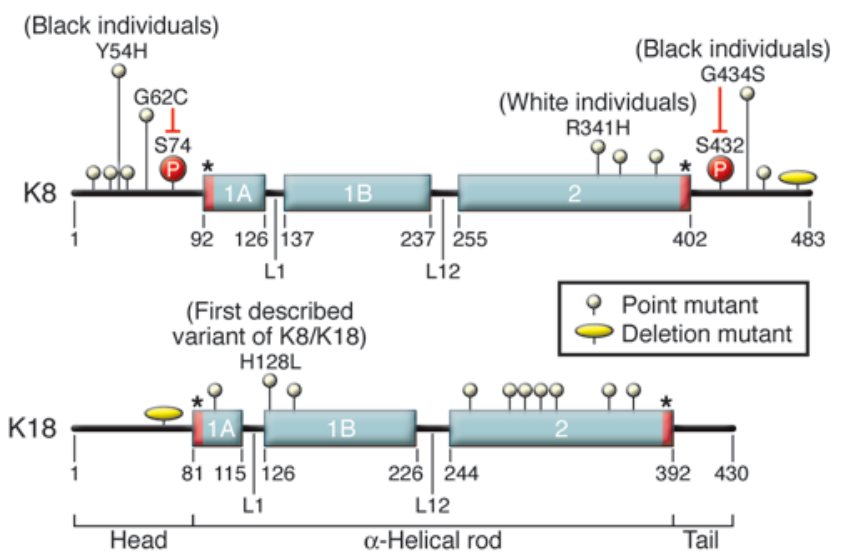

Figure 2

Overview of K8 and K18 mutations. Shown are the domain organization of the protein backbone of $\mathrm{K} 8$ and $\mathrm{K} 18$ and the general distribution of different point mutations and deletions. K8 Y54H, G62C, $\mathrm{R} 341 \mathrm{H}$, and $\mathrm{G} 434 \mathrm{~S}$ variants are found in patients with liver disease, but show a strong ethnic distribution. The first described SEK variant was $\mathrm{K} 18 \mathrm{H} 128 \mathrm{~L}$ (74). In white individuals, the most common K8 variant is $\mathrm{R} 341 \mathrm{H}$, while the most common amino acid-altering variant in black individuals is G434S. The 2 human mutations, K8 G62C and G434S, inhibit the phosphorylation of the adjacent $S 74$ and S432, respectively. Notably, transgenic mice that express K8 G62C phenocopy the marked predisposition to liver injury observed in mice that express the phosphomutant K8 S74A. Asterisks at the beginning and end of the rod domain highlight the helix initiation and helix termination motifs that include mutation hot spots for epidermal keratins, and for IFs in general, but not for the SEKs. The assignment of the specific location of the keratin subdomains was obtained from the Human Intermediate Filament Database (http://www.interfil.org/proteinsTypelnll.php) and includes the start methionine residue. Most individuals with keratin mutations that are at increased risk of liver disease are heterozygous for the mutations, with few patients harboring compound heterozygous mutations. K19 variants are not included in this schematic since they are newly identified (91) and have not been characterized in the detail that $\mathrm{K} 8$ and $\mathrm{K} 18$ variants have.

including the liver, intestine, and pancreas. Surprisingly, in mouse pancreas, neither the absence of K8 (which results in the absence of acinar cell keratin filaments) nor the presence of the K18 R90C mutant (which results in disrupted acinar cell keratin filaments) cause predisposition to pancreatic injury $(20,76)$. This is likely to be related to compensatory induction of regenerating islet-derived II (RegII), which plays a protective role in the pancreas (77) and, in the case of K8-deficient pancreata, may be also related to compensatory overexpression of actin and tubulin (32). Moreover, the chronic pancreatitis caused by overexpression of human K8 in mice (78) is likely to be related to high expression levels being cytotoxic, as demonstrated using transgenic mice that express varying levels of K8 and K18 (Table 2 and ref. 79). In the intestine, redundancy of SEK expression is likely to contribute to the lack of mutationrelated phenotypes observed upon transgenic expression of either dominant-negative K18 or mutant forms of K20 (80).

Transgenic mouse studies have also helped our understanding of how naturally occurring human mutations in the genes encoding SEKs predispose to liver disease (Table 2 and Figure 2). For example, overexpression of the natural human G62C K8 mutant in transgenic mice led to a remarkable predisposition to hepato- cyte apoptosis and liver injury (70). This predisposition was related to a mutation-mediated conformational change that blocks K8 S74 phosphorylation by stress kinases $(70,81)$ and was further confirmed after generation of transgenic mice that overexpress K8 S74A, which phenocopy the K8 G62C mice (70). The general importance of SEK phosphorylation in protecting cells from stress is also supported by the increased predisposition to liver injury in mice that overexpress the S53A K18 phosphomutant (82). In addition, transgenic mice that overexpress the S34A K18 mutant, which blocks S34 phosphorylation during mitosis, can no longer bind 14-3-3 proteins, thereby interfering with the translocation of 14-3-3 proteins from the nucleus to the cytoplasm after partial hepatectomy and leading to limited mitotic arrest (83). Collectively, these genetically engineered mice ultimately led to the association of keratin mutations with human liver disease and to understanding some of the involved pathogenic mechanisms.

\section{SEK variants in human disease}

Mutations in the genes encoding keratins cause several human diseases, with the affected organs reflecting the unique expression pattern of the specific keratin $(4,11)$. Indeed, mutations in genes encoding keratins that are not SEKs cause several tissue-specific diseases with near-complete penetrance, as is the case for mutations in KRT5 and KRT14, which cause epidermolysis bullosa simplex (84). Conversely, mutations in the genes encoding K8 and K18 are risk factors for disease, rather than causative. This is likely to be related to the location of the mutations, which do not overlap with the mutation hot spots at the end and beginning of the rod domain that typically cause more severe disease (Figure 1A and refs. 84, 85). The mechanisms by which KRT8 and KRT18 mutations predispose to disease are discussed below (see How clinical and experimental observations lead to understanding of the function and utility of SEKs in normal health and disease).

The association of SEK variants with human acute and chronic liver disease is supported by numerous studies. In the setting of acute liver disease, germline-encoded KRT8 variants are substantially overrepresented, and their presence is predictive of death or the need for liver transplantation (P. Strnad and M.B. Omary, unpublished observations). For chronic liver disease, KRT8 and KRT18 variants are similarly overrepresented in patients with endstage liver disease of multiple etiologies (odds ratio, 3.7 ; $95 \%$ confidence interval, 2.0-6.8; ref. 12). This increased risk is greater than the 2.6-fold increased risk of myocardial infarction in smokers of 10-19 cigarettes per day versus nonsmokers (12).

The association of SEK variants with inflammatory bowel disease (IBD), in contrast to findings in mice and to the association of $\mathrm{K} 8 / \mathrm{K} 18$ variants with human liver disease, is likely to be limited at best (Figure 1B and refs. 86, 87). Although K8 variants were noted in some patients with IBD (88), an assessment of a large cohort of patients, primarily with familial IBD, did not provide a strong association (87). In addition, there is no evidence of SEK variant association with human pancreatitis based on analysis of 2 large cohorts of patients $(89,90)$ and further supported by transgenic mouse studies $(20,76,79)$. For K19, there is no apparent evidence of variant involvement with IBD (87), and PBC is the first human disease to be associated with $\mathrm{K} 19$ - and K8 - variants (91).

The distribution of $\mathrm{K} 8$ and $\mathrm{K} 18$ mutations within the protein backbone varies. For example, known K8 mutations occur throughout the head, rod, and tail domains, whereas K18 mutations are found primarily in the rod (one exception being a head 


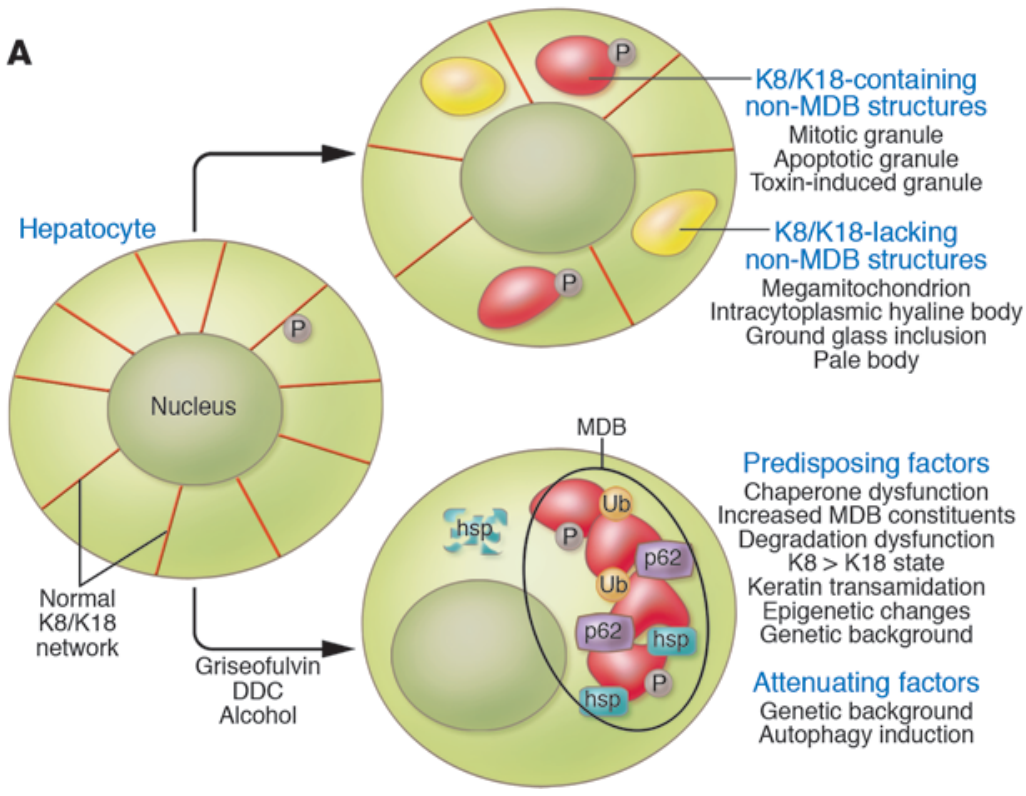

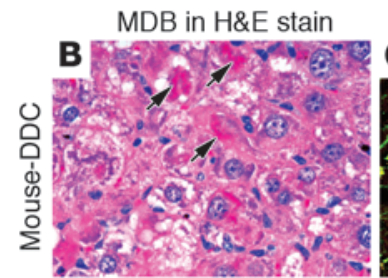
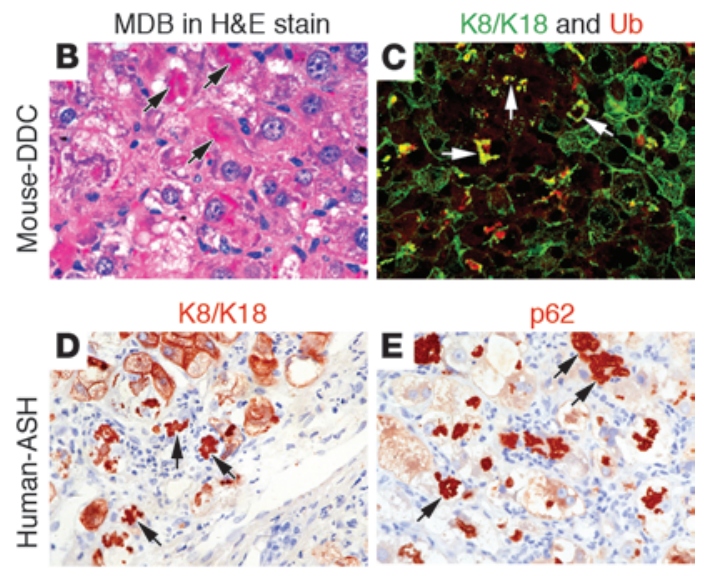

Figure 3

Mechanisms and factors involved in MDB formation. (A) Keratin filament reorganization into deposits, granules, or aggregates involves several physiologic (e.g., mitosis and apoptosis) and pathologic (e.g., aggregates that include or exclude K8 and K18 found in the context of several liver disorders) conditions that result in MDB or non-MDB structures. Ub, ubiquitin. (B-E) MDBs (arrows) are identified by pathologists, using H\&E staining, as eosinophilic structures (B). Alternatively, MDBs can be visualized by immunofluorescence (C) or by immunohistochemical staining using K8- and K18-specific antibodies (C, green signal, and D), ubiquitin (C, red signal), and p62-specific antibodies (E). The immunological detection methods offer greater sensitivity and specificity than histological MDB staining; however, the latter is currently used clinically and is broadly accepted. Note the similar morphology of MDBs that are identified in mice fed DDC and seen in humans with alcoholic steatohepatitis (ASH).

domain deletion of 8 amino acids; Figure 2) and are far less frequent than $\mathrm{K} 8$ variants. The most common amino acid-altering variant in white American and European populations is K8 R341H (12). The importance of this $\mathrm{K} 8$ variant is supported both by animal model studies (Table 2), with protein structural predictions suggesting that $\mathrm{R} 341 \mathrm{H}$ might lead to keratin destabilization, and by its substantial overrepresentation in patients with end-stage liver disease versus controls (92). There is no selective gender difference in $\mathrm{K} 8$ and $\mathrm{K} 18$ variant frequency, but there are remarkable differences in ethnic background preponderance for the K8 Y54H and G434S variants (Figure 2). For example, 6 of 26 (23.1\%) African-American patients had 1 of these 2 variants, versus 1 of 274 (0.4\%) white patients $(P<0.0001$; ref. 92). Furthermore, K8 Y54H was found in 17 of 722 (2.4\%) Africans but in 1 of 1,532 (0.1\%) Germans (90), lending further credence to the near exclusivity of this variant to African origin. One likely explanation for the relative frequency of the $\mathrm{K} 8 \mathrm{R} 341 \mathrm{H}$ and $\mathrm{G} 434 \mathrm{~S}$ variants is the deamination of methylated cytosine in the context of a CpG dinucleotide, the most frequent type of mutation in the human genome (93).

Not all likely disease-related variants show overrepresentation in patients with liver disease versus controls. This is particularly the case for less common variants and because some variants are silent unless the carrier is exposed to a liver insult. For example, K8 G62C has been identified in 6 of 467 (1.3\%) US patients with liver disease versus 9 of $963(0.9 \%)$ controls $(P>0.5)$ and in 37 of 2,255 (1.6\%) German patients with liver disease versus 88 of 6,061 (1.5\%) controls $(P>0.5$; ref. 12). However, K8 G62C expression in mice (70) results in marked predisposition to liver injury (Table 2). Hence, most individual keratin variants are silent under basal conditions, but provide a genetic first hit that is uncovered by the second hit of liver injury. In addition, as the allele frequency is less than $1 \%-2 \%$ in the population of many SEK variants that are likely to be pathogenic, based on animal models and other in vitro supportive evidence, data from analyses of different variants of a given SEK are pooled to provide adequate numbers to compare the frequency of mutation of the SEK in control and liver disease cohorts. Infection with HCV is one potential second hit, and one report has shown that individuals with $\mathrm{K} 8$ variants (as a group) are overrepresented in infected patients with advanced versus early fibrosis, independent of age or other comorbid factors (94). Association of SEK mutations with liver fibrosis progression is further supported by findings in K18 R90C mice, which develop thioacetamide-induced fibrosis that is substantially more severe than that in controls (95).

\section{$\mathrm{K} 8$ and $\mathrm{K} 18$ are the major constituents of MDBs}

MDBs were first described by Frank Mallory approximately 100 years ago as cytoplasmic hepatocyte hyaline inclusions, and then renamed Mallory-Denk bodies to honor the contributions of Helmut Denk (13). K8 and K18 are the major constituents of MDBs, which are also composed of ubiquitin and the ubiquitin-binding protein p62. MDBs are found primarily in hepatocytes of individuals with alcoholic and nonalcoholic steatohepatitis, but can also be seen in the hepatocytes of patients with $\mathrm{PBC}$, hepatocellular carcinomas, and copper metabolism disorders (13). The major determinants for MDB formation are outlined briefly here and in Figure 3A (12). First, there is induction of K8 and K18 expression (typically 3-fold induction at the protein level), resulting in K8 levels outweighing 


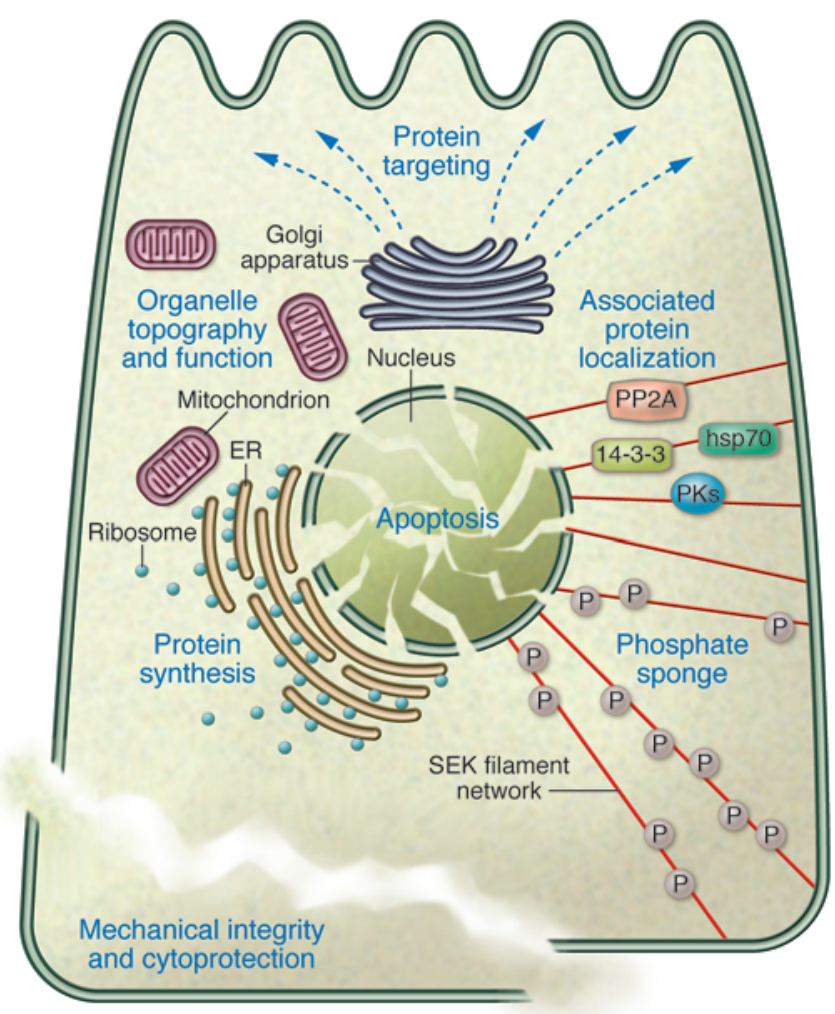

those of K18. Second, there is transamidation of keratins by transglutaminase-2 (TG2). The excess K8, a superior TG2 substrate compared with $\mathrm{K} 18$, is not protected by its heterodimer K18, rendering it more accessible for crosslinking (96). Third, the presence of $\mathrm{p} 62$ - and likely its upregulation - is essential $(97,98)$. Fourth, there must be several genetic modifiers, which remain to be defined, given the dramatic mouse strain difference in susceptibility to MDB formation (99). Fifth, there are epigenetic factors affecting DNA methylation and consequent gene expression that affect MDB formation (100). Last, proteasome inhibition promotes, but does not directly cause, mouse MDB formation in vivo (101). Such inhibition can mimic proteasome overutilization when coupled with a decrease in chaperone levels and function (102) and is consistent with the observation that MDB formation is paralleled by increased protein misfolding and $\beta$-sheet formation $(103,104)$.

In mice, aggregates that biochemically and ultrastructurally resemble MDBs can be induced by feeding either of the hepatotoxic drugs griseofulvin or 3,5-diethoxycarbonyl-1,4-dihydrocollidine (DDC) for 3-4 months (13). While DDC- or griseofulvin-induced aggregates largely mimic the MDBs seen in humans (Figure 3B), some differences exist, including the prominent porphyria and the limited steatosis associated with the mouse model (12). Formation of both human and mouse MDB is reversible, and MDBs largely disappear when patients eliminate alcohol consumption and when mice are reverted to a drug-free diet for 1 month or more. Furthermore, autophagy activation by rapamycin leads to both prevention of mouse MDB formation and resorption of preformed MDBs (Figure 3A and ref. 101). However, there is a toxic memory that leads to rapid MDB reformation in mice that have recovered after DDC or griseofulvin feeding (termed primed mice) when they are exposed for 5-7 days to any one of a variety of hepatotoxins

\section{Figure 4}

Summary of SEK functions. The various SEK functions, which contribute to the major role of SEKs as cytoprotectors, are interrelated and include: providing mechanical integrity; modulating protein localization, targeting, and/or synthesis via association with other proteins (e.g., hsp70, 14-3-3 proteins, Fas receptor, protein kinases [PKs], and phosphatases such as protein phosphatase-2A [PP2A]); contributing to the positioning and function of organelles such as mitochondria and Golgi; serving as a phosphate "sponge" under stress (e.g., via phosphorylation of K8 S74); and protecting the cells from undergoing apoptosis.

that normally do not induce MDBs (13). One likely cause of this memory is a long-term loss of chaperone function that requires a long recovery period, possibly as a result of slow turnover of modified and functionally altered stress proteins (102).

The morphologic description of MDBs in the clinical setting entails routine H\&E staining (12). An extended definition of MDBs relies on biochemical MDB composition rather than morphological criteria. This approach involves either immunohistochemical staining (105), which adds specificity (e.g., presence of K8 and K18), or the more sensitive and specific double/triple immunofluorescence staining (e.g., for keratin, ubiquitin, and p62), which can also detect smaller aggregates not seen by routine histology staining (Figure 3, $\mathrm{C}-\mathrm{E}$, and refs. 12, 13). Indeed, immunofluorescence staining detects small granules, considered early or pre-MDBs, that can outnumber by 30 - to 90 -fold the typical large MDB granules but may not parallel their presence when tested in several mouse strains (99). Furthermore, several biologic contexts can generate non-MDB, K8/ K18-containing deposits or inclusions, but these inclusions do not contain p62 or ubiquitin (Figure 3A). It remains to be determined whether more sensitive detection of MDBs will provide selective diagnostic or prognostic benefits. Presently, the broadly used histological assessment of MDBs primarily provides an important aid for determining liver disease etiology, but whether MDBs provide protective or detrimental outcomes to an MDB-containing hepatocyte remains unclear $(12,13)$.

\section{Autoantibodies specific for SEKs in human disease}

Autoantibodies specific for SEKs have been reported in autoimmune and malignant liver diseases. A subset of patients with autoimmune hepatitis (AIH) harbors high titers of antibodies specific for K8, K18, and K19 that decrease after steroid treatment (106). Moreover, K8- and K18-specific antibodies have been detected in patients with de novo AIH after liver transplantation, whereas liver transplant recipients without de novo AIH were seronegative for these antibodies (107). Presumably, such antibodies develop as a consequence of recurrent or chronic cell death, which leads to exposure of the immune system to cytoplasmic proteins that are otherwise absent in the circulation. This hypothesis can be readily tested in liver transplant patients who harbor other post-transplantation recurrent liver diseases.

Other SEK-targeted autoantibodies include antibodies specific for K8/K18; these have been found in association with cryptogenic acute liver failure, which may suggest an autoimmune pathogenesis (108). In addition, proteomic analysis revealed an increased frequency of $\mathrm{K} 8$-specific antibodies in patients with hepatocellular carcinoma compared with patients with chronic viral hepatitis. However, these results are controversial $(109,110)$. Similar to the situation of SEK serum markers, the presence of SEK-specific autoantibodies may provide potentially useful clinical tools for 
diagnosis and determining prognosis and treatment response, but additional studies are required.

\section{How clinical and experimental observations lead to understanding of the function and utility of SEKs in normal health and disease}

The major function of SEKs is to serve as cytoprotectors via protecting from apoptosis and providing mechanical integrity to cells (Figure 4 and refs. 12, 41, 71). The mechanical resilience role of keratins is exemplified by the marked fragility of K8-deficient, K18-deficient, and K18 R90C hepatocytes, as assessed by liver perfusion $(68,70,72)$. The mechanical properties of keratins are endowed by their unique biophysical flexibility to resist deformations compared with other cytoskeletal proteins as well as by their ability to stretch more than 3 times their original length before breaking (111). However, it is unclear whether mechanical stress plays a direct physiological role in K8, K18, and K19 variant predisposition to liver disease progression. One hypothesis, which has not yet been tested, is that the increased portal pressure associated with liver fibrosis contributes to enhanced liver injury in carriers of keratin variants by affecting hepatocyte fragility.

All human natural SEK variants tested to date do not have a direct effect on keratin filament organization upon cell transfection (92) under basal conditions. In transgenic mice, the K8 G62C variant does not affect hepatocyte fragility upon liver perfusion (70), unlike the K18 R90C variant, which increases hepatocyte fragility dramatically upon liver perfusion (72). This suggests that most of the natural human mutations do not have a direct effect on hepatocyte fragility. However, natural human SEK mutations (e.g., K8 Y54H and G62C) do have an effect on stimulus-mediated keratin filament reorganization in cell transfection systems exposed to chemical or oxidative stress (75), which may have a hitherto untested secondary role on cell fragility. Hence, other nonmechanical functions of SEKs (Figure 4) are likely to be equally important as, if not more so than, direct mechanical SEK function in the context of SEK functional alterations in human disease.

The nonmechanical functions of SEKs include a role in protein localization and targeting, in modulating protein synthesis, and in contributing to epithelial cell polarity $(9,10)$. This is supported by studies involving K8-deficient intestine and liver and K18 R90Cexpressing cultured cells. In K8-deficient small and large intestine, there is mistargeting of ion transporters that likely accounts for the observed diarrhea in these animals $(67,112)$. Under basal conditions, K8-deficient hepatocytes display increased basolateral distribution of the bile canaliculus Ecto-ATPase (112), increased apical distribution of the Fas receptor (113), and reduced desmoplakin deposition at desmosomes (114). Furthermore, K18 R90C-expressing cells form keratin aggregates containing peripheral membrane (desmoplakin/zonula occludens- $1 / \beta$-catenin) and cytosolic (14-3-3 $\zeta /$ glucose-6-phosphate dehydrogenase) proteins and show redistribution of E-cadherin (115). The role of keratins in protein synthesis was demonstrated by the importance of epidermal keratins in promoting protein synthesis and cell size growth through K17 association with 14-3-3 proteins (116) and by the association of several skin keratins with eukaryotic elongation factor-1 $\gamma$-subunit (117). Similar findings were observed in K8-deficient hepatocytes, which are smaller than their wild-type counterparts and have decreased rates of protein synthesis (118).

SEKs are also involved in regulating the dynamic interaction of a growing list of keratin-associated proteins that includes hsp70 and numerous cell signaling proteins, including 14-3-3 proteins, Raf-1 kinase, p38 and Jun kinases, $\mathrm{PKC}$, and protein phosphatase-2A $(61,119)$. For example, Raf-1 kinase associates with K8/K18 under basal conditions, but is released from keratins and activated (to phosphorylate other Raf substrates) in a phosphorylation-dependent manner during oxidative stress (120). This keratin guardian role also extends, in the case of $\mathrm{K} 8$, to an antiapoptotic function by serving as a hepatocyte phosphate "sponge" during stress. This protection is mediated by K8 S74 phosphorylation, which appears to shunt away unwarranted phosphorylation of proapoptotic substrates such as c-Jun, CREB, and p90RSK (70). The antiapoptotic role of SEKs is likely to be multifactorial and may include increased cell surface Fas receptors, as noted in K8-null hepatocytes (113).

The emerging importance of IFs, including SEKs, in organelle positioning and function is also likely to be important in disease pathogenesis (9). In general, fragmentation of organelles, such as mitochondria and Golgi, is related to apoptosis and is a critical factor in the pathogenesis of neurodegenerative disorders $(121,122)$. For example, K18 R90C-transfected cells have Golgi scattered around keratin aggregates instead of their usual juxtanuclear clustering (123) and also have fragmented mitochondria (124). In vivo, both K8-deficient and K18 R90C hepatocyte mitochondria are markedly smaller and display irregular cytoplasmic distribution. K8-deficient mitochondria also have less ATP and cytochrome $c$ content and lower permeability transition (M.B. Omary, unpublished observations). These organelle keratin-associated functional and organizational properties may reflect a mechanical functional contribution by SEKs, but this area is presently wide open for investigation.

\section{Conclusions and future perspectives}

We have defined here SEKs as K7, K8, K18-K20, and K23. Of these, the abundant SEKs are K8 and K18-K20, with K8 and K18 being the most abundant (based on visualization by routine Coomassie blue dye staining after extraction from relevant tissues; ref. 14). Other newly appreciated and less-studied keratins, such as K24 (18), may ultimately be grouped with the less abundant SEKs K7 and K23. Mutations in the genes encoding SEKs, specifically KRT8, $K R T 18$, and KRT19, render their carriers greater than 3.5-fold more susceptible to liver disease progression and, in this context, provide a general genetic first hit in chronic and acute liver disease predisposition that may be compounded by additional insults such as toxins and viral infection. To assess the relative importance of SEK mutations in acute and chronic liver disease, specific liver disorders will need to be investigated, and ethnic-related variants may be identified. The identification of the K8 variants $\mathrm{Y} 54 \mathrm{H}$ and G434S nearly exclusively with individuals of African descent may confer an evolutionary benefit that is independent of their predisposition to liver disease. Extending the present findings with regard to KRT8, KRT18, and KRT19 as susceptibility genes to liver disease, and considering the broad epithelial distribution of SEKs, we hypothesize that keratins may serve as pan-gene modifiers for a spectrum of additional diseases (Figure 1B).

Several unique features distinguish SEKs (especially K8 and K18) from other keratins, particularly those in the epidermis, which have been extensively studied from a disease perspective but less so from a regulation perspective. First, all known SEK human mutations exclude the ends of the rod domain, which likely explains why these mutations predispose to, rather than cause, disease. Should such SEK mutations exist in humans, they are likely to be embryo lethal (12). Second, SEKs are far more soluble on a percentile basis (5\%-10\% 
of total cell SEK) than other keratins, particularly epidermal keratins (less than 1\%) (6). The molar concentration of the soluble fractions is not known, but is dynamic (6). Third, the expression level of SEKs, despite their abundance (up to $5 \%$ of total cell protein), is far less than epidermal keratins (up to $50 \%$ of total cell protein). This may have context-dependent functions such as formation of an appropriate skin barrier in the case of epidermal keratins. Fourth, SEKs are essential for the generation of hepatocyte MDBs, which share several features with other IF-related and non-IF-related inclusions $(11,13)$, but no such characteristic MDB-like inclusions are well described for other keratins. Furthermore, even within the SEK subgroup of keratins, these inclusions are unique to the liver. It remains unclear whether this represents a keratin-specific and/or cell-specific determinant that may relate to differences in oxidative stress, autophagy and chaperone expression, ubiquitinylation and transamidation, and protein turnover (13).

Although a growing list of functions is attributed to SEKs, their best-characterized role is in cytoprotection via mechanical and nonmechanical means. The nonmechanical roles of SEKs remain to be further explored, particularly with regard to how SEKs modulate apoptosis, serve as scaffolds, modulate protein synthesis and protein targeting, contribute to epithelial polarity, and regulate interactions with an increasing array of binding proteins. Furthermore, keratin expression in high-turnover simple epithelial organs, such as the intestine, is highly complex and somewhat compartmentalized within specific enterocyte subpopulations. Yet the functional implications of this distribution are poorly understood, as is the function of the less abundant SEKs K7, K19, $\mathrm{K} 20$, and K23. Hence, the complex yet very interesting web of SEKs provides a ripe area for further study.

\section{Acknowledgments}

We are grateful to Helmut Denk for providing us with several liverstained images, Pierre Coulombe for reading the manuscript and providing suggestions, and Kris Morrow for assistance with figure preparation. We are also indebted to all the patients and other donors who have made it possible to carry out the genetic and biochemical studies related to SEKs. The authors' work is supported by NIH grants DK47918 and DK52951 and the Department of Veterans Affairs (to M.B. Omary); by Korean Research WCU grant R31-2008-000-10086-0 (to N.-O. Ku); and by German Research Foundation grant STR 1095/1-1 (to P. Strnad).

Address correspondence to: M. Bishr Omary, University of Michigan Medical School, Department of Molecular and Integrative Physiology, 7744 Medical Science II, 1301 E. Catherine Street, Ann Arbor, Michigan 48109-5622, USA. Fax: (734) 936-8813; E-mail: mbishr@umich.edu.
1. Fuchs, E., and Cleveland, D.W. 1998. A structural scaffolding of intermediate filaments in health and disease. Science. 279:514-519.

2. Ku, N.O., Zhou, X., Toivola, D.M., and Omary, M.B. 1999. The cytoskeleton of digestive epithelia in health and disease. Am. J. Physiol. 277:G1108-G1137.

3. Schweizer, J., et al. 2006. New consensus nomenclature for mammalian keratins. J. Cell Biol. 174:169-174.

4. Coulombe, P.A., and Omary, M.B. 2002. "Hard" and "soft" principles defining the structure, function and regulation of keratin intermediate filaments. Curr. Opin. Cell Biol. 14:110-122.

5. Herrmann, H., Strelkov, S.V., Burkhard, P., and Aebi, U. 2009. Intermediate filaments: primary determinants of cell architecture and plasticity. J. Clin. Invest. 119:1772-1783.

6. Omary, M.B., Ku, N.O., Liao, J., and Price, D. 1998. Keratin modifications and solubility properties in epithelial cells and in vitro. Subcell Biochem. 31:105-140.

7. Quinlan, R.A., et al. 1986. Characterization of dimer subunits of intermediate filament proteins. J. Mol. Biol. 192:337-349.

8. Moll, R., Franke, W.W., Schiller, D.L., Geiger, B., and Krepler, R. 1982. The catalog of human cytokeratins: patterns of expression in normal epithelia, tumors and cultured cells. Cell. 31:11-24.

9. Toivola, D.M., Tao, G.Z., Habtezion, A., Liao, J., and Omary, M.B. 2005. Beyond cellular integrity: organelle-related and protein-targeting functions of intermediate filaments. Trends Cell Biol. 15:608-617.

10. Oriolo, A.S., Wald, F.A., Ramsauer, V.P., and Salas, P.J. 2007. Intermediate filaments: a role in epithelial polarity. Exp. Cell Res. 313:2255-2264.

11. Omary, M.B., Coulombe, P.A., and McLean, W.H. 2004. Intermediate filament proteins and their associated diseases. N. Engl. J. Med. 351:2087-2100.

12. Ku, N.O., Strnad, P., Zhong, B.H., Tao, G.Z., and Omary, M.B. 2007. Keratins let liver live: mutations predispose to liver disease and crosslinking generates Mallory-Denk bodies. Hepatology. 46:1639-1649

13. Zatloukal, K., et al. 2007. From Mallory to Mallory-Denk bodies: What, how and why? Exp. Cell Res. 313:2033-2049.
14. Ku, N.O., et al. 2004. Studying simple epithelial keratins in cells and tissues. Methods Cell Biol. 78:489-517.

15. Moll, R., Divo, M., and Langbein, L. 2008. The human keratins: biology and pathology. Histochem. Cell Biol. 129:705-733.

16. Zhang, J.S., Wang, L., Huang, H., Nelson, M., and Smith, D.I. 2001. Keratin 23 (K23), a novel acidic keratin, is highly induced by histone deacetylase inhibitors during differentiation of pancreatic cancer cells. Genes Chromosomes Cancer. 30:123-135.

17. Birkenkamp-Demtroder, K., et al. 2007. Phosphoprotein Keratin 23 accumulates in MSS but not MSI colon cancers in vivo and impacts viability and proliferation in vitro. Mol. Oncol. 1:181-195.

18. Rogers, M.A., Winter, H., Langbein, L., Bleiler, R., and Schweizer, J. 2004. The human type I keratin gene family: characterization of new hair follicle specific members and evaluation of the chromosome $17 \mathrm{q} 21.2$ gene domain. Differentiation. 72:527-540.

19. Zhong, B., et al. 2004. Organ-specific stress induces mouse pancreatic keratin overexpression in association with NF-\{kappa\}B activation. J. Cell Sci. 117:1709-1719.

20. Toivola, D.M., Baribault, H., Magin, T., Michie, S.A., and Omary, M.B. 2000. Simple epithelial keratins are dispensable for cytoprotection in two pancreatitis models. Am. J. Physiol. Gastrointest. Liver. Physiol. 279:G1343-G1354.

21. Fradette, J., Germain, L., Seshaiah, P., and Coulombe, P.A. 1998. The type I keratin 19 possesses distinct and context-dependent assembly properties. J. Biol. Chem. 273:35176-35184.

22. Lu, H., Hesse, M., Peters, B., and Magin, T.M. 2005. Type II keratins precede type I keratins during early embryonic development. Eur. J. Cell Biol. 84:709-718.

23. Omary, M.B., Ku, N.O., and Toivola, D.M. 2002. Keratins: Guardians of the liver. Hepatology. 35:251-257.

24. Moll, R., Hage, C., and Thoenes, W. 1991. Expression of intermediate filament proteins in fetal and adult human kidney: modulations of intermediate filament patterns during development and in damaged tissue. Lab. Invest. 65:74-86.

25. Van Eyken, P., Sciot, R., and Desmet, V.J. 1988. A cytokeratin immunohistochemical study of alcoholic liver disease: evidence that hepatocytes can express 'bile duct-type' cytokeratins. Histopathology. 13:605-617.

26. Zhou, Q., et al. 2006. Keratin 20 serine-13 phosphorylation is a stress and intestinal goblet cell marker. J. Biol. Chem. 281:16453-16461.

27. Cadrin, M., Hovington, H., Marceau, N., and McFarlane-Anderson, N. 2000. Early perturbations in keratin and actin gene expression and fibrillar organisation in griseofulvin-fed mouse liver. J. Hepatol. 33:199-207.

28. Denk, H., Stumptner, C., and Zatloukal, K. 2000. Mallory bodies revisited. J. Hepatol. 32:689-702.

29. Tao, G.Z., et al. 2003. Keratin-8 null mice have different gallbladder and liver susceptibility to lithogenic diet-induced injury. J. Cell Sci. 116:4629-4638.

30. Fickert, P., et al. 2003. Mallory body formation in primary biliary cirrhosis is associated with increased amounts and abnormal phosphorylation and ubiquitination of cytokeratins. J. Hepatol. 38:387-394.

31. Jaitovich, A., et al. 2008. Ubiquitin-proteasomemediated degradation of keratin intermediate filaments in mechanically stimulated A549 cells. J. Biol. Chem. 283:25348-25355.

32. Zhong, B., and Omary, M.B. 2004. Actin overexpression parallels severity of pancreatic injury. Exp. Cell Res. 299:404-414.

33. Chu, P.G., and Weiss, L.M. 2002. Keratin expression in human tissues and neoplasms. Histopathology. 40:403-439.

34. Tot, T. 2002. Cytokeratins 20 and 7 as biomarkers: usefulness in discriminating primary from metastatic adenocarcinoma. Eur. J. Cancer. 38:758-763.

35. Lehr, H.A., Folpe, A., Yaziji, H., Kommoss, F., and Gown, A.M. 2000. Cytokeratin 8 immunostaining pattern and E-cadherin expression distinguish lobular from ductal breast carcinoma. Am. J. Clin. Pathol. 114:190-196.

36. McGregor, D.K., Wu, T.T., Rashid, A., Luthra, R., and Hamilton, S.R. 2004. Reduced expression of cytokeratin 20 in colorectal carcinomas with high levels of microsatellite instability. Am. J. Surg. Pathol. 28:712-718.

37. Woelfle, U., Sauter, G., Santjer, S., Brakenhoff, R., and Pantel, K. 2004. Down-regulated expression of cytokeratin 18 promotes progression of human 
breast cancer. Clin. Cancer Res. 10:2670-2674.

38. Buhler, H., and Schaller, G. 2005. Transfection of keratin 18 gene in human breast cancer cells causes induction of adhesion proteins and dramatic regression of malignancy in vitro and in vivo. $\mathrm{Mol}$. Cancer Res. 3:365-371.

39. Linder, S. 2007. Cytokeratin markers come of age. Tumour Biol. 28:189-195.

40. Leers, M.P., et al. 1999. Immunocytochemical detection and mapping of a cytokeratin 18 neoepitope exposed during early apoptosis. J. Pathol. 187:567-572.

41. Marceau, N., et al. 2007. Dual roles of intermediate filaments in apoptosis. Exp. Cell Res. 313:2265-2281.

42. Barak, V., Goike, H., Panaretakis, K.W., and Einarsson, R. 2004. Clinical utility of cytokeratins as tumor markers. Clin. Biochem. 37:529-540.

43. Duffy, M.J. 2006. Serum tumor markers in breast cancer: are they of clinical value? Clin. Chem 52:345-351.

44. Nisman, B., et al. 1998. Evaluation of tissue polypeptide specific antigen, CYFRA 21-1, and carcinoembryonic antigen in nonsmall cell lung carcinoma: does the combined use of cytokeratin markers give any additional information? Cancer. 82:1850-1859.

45. Nakayama, M., et al. 2003. Cytokeratin 19 fragment in patients with nonmalignant respiratory diseases. Chest. 123:2001-2006.

46. Gonzalez-Quintela, A., et al. 2006. Serum levels of cytokeratin-18 (tissue polypeptide-specific antigen) in liver diseases. Liver Int. 26:1217-1224.

47. Bantel, H., et al. 2004. Detection of apoptotic caspase activation in sera from patients with chronic $\mathrm{HCV}$ infection is associated with fibrotic liver injury. Hepatology 40:1078-1087.

48. Volkmann, X., et al. 2006. Caspase activation is required for antiviral treatment response in chronic hepatitis $\mathrm{C}$ virus infection. Hepatology. 43:1311-1316.

49. Wieckowska, A., et al. 2006. In vivo assessment of liver cell apoptosis as a novel biomarker of disease severity in nonalcoholic fatty liver disease. Hepatology. 44:27-33.

50. Papatheodoridis, G.V., et al. 2008. Serum apoptotic caspase activity as a marker of severity in HBeAgnegative chronic hepatitis B virus infection. Gut. 57:500-506.

51. Luft, T., et al. 2007. Serum cytokeratin-18 fragments as quantitative markers of epithelial apoptosis in liver and intestinal graft-versus-host disease. Blood. 110:4535-4542.

52. Greystoke, A., et al. 2008. Optimisation of circulating biomarkers of cell death for routine clinical use. Ann. Oncol. 19:990-995.

53. Kramer, G., et al. 2004. Differentiation between cell death modes using measurements of different soluble forms of extracellular cytokeratin 18. Cancer Res. 64:1751-1756.

54. Tao, G.Z., et al. 2008. Monitoring of epithelial cell caspase activation via detection of durable keratin fragment formation. J. Pathol. 215:164-174.

55. Ursitti, J.A., et al. 2004. Cloning and characterization of cytokeratins 8 and 19 in adult rat striated muscle. Interaction with the dystrophin glycoprotein complex. J. Biol. Chem. 279:41830-41838.

56. Stone, M.R., et al. 2007. Absence of keratin 19 in mice causes skeletal myopathy with mitochondrial and sarcolemmal reorganization. J. Cell Sci. 120:3999-4008.

57. Cockerham, G.C., Laver, N.V., Hidayat, A.A., and McCoy, D.L. 2002. An immunohistochemical analysis and comparison of posterior polymorphous dystrophy with congenital hereditary endothelial dystrophy. Cornea. 21:787-791.

58. Jirsova, K., et al. 2007. Immunohistochemical characterization of cytokeratins in the abnormal corneal endothelium of posterior polymorphous corneal dystrophy patients. Exp. Eye Res. 84:680-686.

59. Jahn, L., et al. 1993. Cytokeratins 8 and 18 in smooth muscle cells. Detection in human coronary artery, peripheral vascular, and vein graft disease and in transplantation-associated arteriosclerosis. Arterioscler. Thromb. 13:1631-1639.

60. Moon, M.C., Yau, L., Wright, B., and Zahradka, P. 2008. Injury-induced expression of cytokeratins 8 and 18 by vascular smooth muscle cells requires concurrent activation of cytoskeletal and growth factor receptors. Can. J. Physiol. Pharmacol. 86:223-231.

61. Omary, M.B., Ku, N.O., Tao, G.Z., Toivola, D.M., and Liao, J. 2006. "Heads and tails" of intermediate filament phosphorylation: multiple sites and functional insights. Trends Biochem. Sci. 31:383-394.

62. Bar, H., et al. 2001. Phosphorylation of cytokeratin 8 and 18 in human vascular smooth muscle cells of atherosclerotic lesions and umbilical cord vessels. Basic Res. Cardiol. 96:50-58.

63. Bader, B.L., Jahn, L., and Franke, W.W. 1988. Low level expression of cytokeratins 8,18 and 19 in vascular smooth muscle cells of human umbilical cord and in cultured cells derived therefrom, with an analysis of the chromosomal locus containing the cytokeratin 19 gene. Eur. J. Cell Biol. 47:300-319.

64. Baribault, H., Price, J., Miyai, K., and Oshima, R.G. 1993. Mid-gestational lethality in mice lacking keratin 8. Genes Dev. 7:1191-1202.

65. Baribault, H., Penner, J., Iozzo, R.V., and Wilson-Heiner, M. 1994. Colorectal hyperplasia and inflammation in keratin 8-deficient FVB/ $\mathrm{N}$ mice. Genes Dev. 8:2964-2973.

66. Habtezion, A., Toivola, D.M., Butcher, E.C., and Omary, M.B. 2005. Keratin-8-deficient mice develop chronic spontaneous Th2 colitis amenable to antibiotic treatment. J. Cell Sci. 118:1971-1980.

67. Toivola, D.M., Krishnan, S., Binder, H.J., Singh, S.K., and Omary, M.B. 2004. Keratins modulate colonocyte electrolyte transport via protein mistargeting. J. Cell Biol. 164:911-921.

68. Loranger, A., et al. 1997. Simple epithelium keratins are required for maintenance of hepatocyte integrity. Am. J. Pathol. 151:1673-1683.

69. Magin, T.M. 1998. Lessons from keratin transgenic and knockout mice. Subcell. Biochem. 31:141-172.

70. Ku, N.O., and Omary, M.B. 2006. A disease and phosphorylation related non-mechanical function for keratin 8. J. Cell Biol. 174:115-125.

71. Oshima, R.G. 2002. Apoptosis and keratin intermediate filaments. Cell. Death Differ. 9:486-492.

72. Ku, N.O., Michie, S., Oshima, R.G., and Omary, M.B. 1995. Chronic hepatitis, hepatocyte fragility, and increased soluble phosphoglycokeratins in transgenic mice expressing a keratin 18 conserved arginine mutant. J. Cell Biol. 131:1303-1314.

73. Ku, N.O., et al. 1996. Susceptibility to hepatotoxicity in transgenic mice that express a dominantnegative human keratin 18 mutant. J. Clin. Invest. 98:1034-1046

74. Ku, N.O., Wright, T.L., Terrault, N.A., Gish, R., and Omary, M.B. 1997. Mutation of human keratin 18 in association with cryptogenic cirrhosis. J. Clin. Invest. 99:19-23.

75. Ku, N.O., Gish, R., Wright, T.L., and Omary, M.B. 2001. Keratin 8 mutations in patients with cryptogenic liver disease. N. Engl. J. Med. 344:1580-1587.

76. Toivola, D.M., et al. 2000. Effects of keratin filament disruption on exocrine pancreas-stimulated secretion and susceptibility to injury. Exp. Cell Res. 255:156-170.

77. Zhong, B., et al. 2007. Reg-II is an exocrine pancreas injury-response product that is up-regulated by keratin absence or mutation. Mol. Biol. Cell. 18:4969-4978.

78. Casanova, M.L., et al. 1999. Exocrine pancreatic disorders in transsgenic mice expressing human keratin 8. J. Clin. Invest. 103:1587-1595.

79. Toivola, D.M., et al. 2008. Keratin overexpression levels correlate with the extent of spontaneous pancreatic injury. Am. J. Pathol. 172:882-892.

80. Zhou, Q., et al. 2003. Keratin 20 helps maintain intermediate filament organization in intestinal epithelia. Mol. Biol. Cell. 14:2959-2971.

81. Tao, G.Z., et al. 2006. Bispecific and human diseaserelated anti-keratin rabbit monoclonal antibodies. Exp. Cell Res. 312:411-422.

82. Ku, N.O., et al. 1998. Mutation of a major keratin phosphorylation site predisposes to hepatotoxic injury in transgenic mice. J. Cell Biol. 143:2023-2032.

83. Ku, N.O., Michie, S., Resurreccion, E.Z., Broome, R.L., and Omary, M.B. 2002. Keratin binding to 14-3-3 proteins modulates keratin filaments and hepatocyte mitotic progression. Proc. Natl. Acad. Sci.U.S. A. 99:4373-4378.

84. Coulombe, P.A., Kerns, M.L., and Fuchs, E. 2009. Epidermolysis bullosa simplex: a paradigm for disorders of tissue fragility. J. Clin. Invest. 119:1784-1793.

85. Uitto, J., Richard, G., and McGrath, J.A. 2007. Diseases of epidermal keratins and their linker proteins. Exp. Cell Res. 313:1995-2009.

86. Buning, C., et al. 2004. Keratin 8 Y54H and G62C mutations are not associated with inflammatory bowel disease. Dig. Liver Dis. 36:388-391.

87. Tao, G.Z., et al. 2007. Analysis of keratin polypeptides 8 and 19 variants in inflammatory bowel disease. Clin. Gastroenterol. Hepatol. 5:857-864.

88. Owens, D.W., et al. 2004. Human keratin 8 mutations that disturb filament assembly observed in inflammatory bowel disease patients. J. Cell Sci. 117:1989-1999.

89. Schneider, A., et al. 2006. Keratin 8 mutations are not associated with familial, sporadic and alcoholic pancreatitis in a population from the United States. Pancreatology. 6:103-108.

90. Treiber, M., et al. 2006. Keratin 8 sequence variants in patients with pancreatitis and pancreatic cancer. J. Mol. Med. 84:1015-1022.

91. Zhong, B. et al. 2009. Keratin variants are over-represented in primary biliary cirrhosis and associate with disease severity. Hepatology. In press.

92. Ku, N.O., et al. 2005. Keratins as susceptibility genes for end-stage liver disease. Gastroenterology. 129:885-893.

93. Cooper, D.N., and Youssoufian, H. 1988. The CPG dinucleotide and human genetic disease. Hum. Genet. 78:151-155.

94. Strnad, P., et al. 2006. Keratin variants associate with progression of fibrosis during chronic hepatitis C infection. Hepatology. 43:1354-1363.

95. Strnad, P., et al. 2008. Keratin mutation predisposes to mouse liver fibrosis and unmasks differential effects of the carbon tetrachloride and thioacetamide models. Gastroenterology. 134:1169-1179.

96. Strnad, P., et al. 2007. Transglutaminase 2 regulates mallory body inclusion formation and injury-associated liver enlargement. Gastroenterology. 132:1515-1526.

97. Stumptner, C., Fuchsbichler, A., Zatloukal, K., and Denk, H. 2007. In vitro production of Mallory bodies and intracellular hyaline bodies: the central role of sequestosome 1/p62. Hepatology. 46:851-860.

98. Nan, L., et al. 2004. p62 is involved in the mechanism of Mallory body formation. Exp. Mol. Pathol. 77:168-175.

99. Hanada, S., Strnad, P., Brunt, E.M., and Omary, M.B. 2008. The genetic background modulates susceptibility to mouse liver Mallory-Denk body formation and liver injury. Hepatology. 48:943-952.

100.Li, J., et al. 2008. S-adenosylmethionine prevents Mallory Denk body formation in drug-primed mice by inhibiting the epigenetic memory. Hepatology. 47:613-624.

101.Harada, M., Hanada, S., Toivola, D.M., Ghori, N., and Omary, M.B. 2008. Autophagy activation by rapamycin eliminates mouse Mallory-Denk bodies and blocks their proteasome inhibitor-mediated 
formation. Hepatology. 47:2026-2035.

102.Strnad, P., et al. 2008. "Toxic memory" via chaperone modification is a potential mechanism for rapid Mallory-Denk body reinduction. Hepatology. 48:931-942.

103.Cadrin, M., French, S.W., and Wong, P.T. 1991. Alteration in molecular structure of cytoskeleton proteins in griseofulvin-treated mouse liver: a pressure tuning infrared spectroscopy study. Exp. Mol. Pathol. 55:170-179.

104.Kachi, K., Wong, P.T., and French, S.W. 1993. Molecular structural changes in Mallory body proteins in human and mouse livers: an infrared spectroscopy study. Exp. Mol. Pathol. 59:197-210.

105.Jensen, K., and Gluud, C. 1994. The Mallory body: morphological, clinical and experimental studies (Part 1 of a literature survey). Hepatology. 20:1061-1077.

106. Murota, M., et al. 2001. Anti-cytokeratin antibodies in sera of the patients with autoimmune hepatitis. Clin. Exp. Immunol. 125:291-299.

107.Inui, A., Sogo, T., Komatsu, H., Miyakawa, H., and Fujisawa, T. 2005. Antibodies against cytokeratin $8 / 18$ in a patient with de novo autoimmune hepatitis after living-donor liver transplantation. Liver Transpl. 11:504-507.

108. Bernal, W., et al. 2007. The significance of autoantibodies and immunoglobulins in acute liver failure: a cohort study. J. Hepatol. 47:664-670.

109.Le Naour, F., et al. 2002. A distinct repertoire of autoantibodies in hepatocellular carcinoma identified by proteomic analysis. Mol. Cell Proteomics. 1:197-203.

110.Li, L., Chen, S.H., Yu, C.H., Li, Y.M., and Wang, S.Q. 2008. Identification of hepatocellular-carcinomaassociated antigens and autoantibodies by serological proteome analysis combined with protein microarray. J. Proteome Res. 7:611-620.

111.Wagner, O.I., et al. 2007. Softness, strength and self-repair in intermediate filament networks. Exp. Cell Res. 313:2228-2235.

112.Ameen, N.A., Figueroa, Y., and Salas, P.J. 2001. Anomalous apical plasma membrane phenotype in CK8-deficient mice indicates a novel role for intermediate filaments in the polarization of simple epithelia. J. Cell Sci. 114:563-575.

113.Gilbert, S., Loranger, A., Daigle, N., and Marceau, N. 2001. Simple epithelium keratins 8 and 18 provide resistance to Fas-mediated apoptosis. The protection occurs through a receptor-targeting modulation. J. Cell Biol. 154:763-773.

114.Loranger, A., Gilbert, S., Brouard, J.S., Magin, T.M., and Marceau, N. 2006. Keratin 8 modulation of desmoplakin deposition at desmosomes in hepatocytes. Exp. Cell Res. 312:4108-4119.

115. Hanada, S., et al. 2005. Keratin-containing inclusions affect cell morphology and distribution of cytosolic cellular components. Exp. Cell Res. 304:471-482.

116.Kim, S., Wong, P., and Coulombe, P.A. 2006. A keratin cytoskeletal protein regulates protein synthesis and epithelial cell growth. Nature. 441:362-365.

117. Kim, S., Kellner, J., Lee, C.H., and Coulombe, P.A. 2007. Interaction between the keratin cytoskeleton and eEF1Bgamma affects protein synthesis in epithelial cells. Nat. Struct. Mol. Biol. 14:982-983.

118. Galarneau, L., Loranger, A., Gilbert, S., and Marceau, N. 2007. Keratins modulate hepatic cell adhesion, size and G1/S transition. Exp. Cell Res. 313:179-194.

119.Liao, J., Lowthert, L.A., Ghori, N., and Omary, M.B. 1995. The $70-\mathrm{kDa}$ heat shock proteins associate with glandular intermediate filaments in an ATPdependent manner. J. Biol. Chem. 270:915-922.

120. Ku, N.O., Fu, H., and Omary, M.B. 2004. Raf-1 activation disrupts its binding to keratins during cell stress. J. Cell Biol. 166:479-485.

121. Frank, S. 2006. Dysregulation of mitochondrial fusion and fission: an emerging concept in neuro- degeneration. Acta Neuropathol. 111:93-100

122. Gonatas, N.K., Stieber, A., and Gonatas, J.O. 2006. Fragmentation of the Golgi apparatus in neurodegenerative diseases and cell death. J. Neurol. Sci. 246:21-30.

123. Kumemura, H., et al. 2004. Aggregation and loss of cytokeratin filament networks inhibit golgi organization in liver-derived epithelial cell lines. Cell Motil. Cytoskeleton. 57:37-52.

124.Kumemura, H., et al. 2008. Mutation in keratin 18 induces mitochondrial fragmentation in liverderived epithelial cells. Biochem. Biophys. Res. Commun. 367:33-40.

125.Nurgalieva, Z., Lowrey, A., and El-Serag, H.B. 2007. The use of cytokeratin stain to distinguish Barrett's esophagus from contiguous tissues: a systematic review. Dig. Dis. Sci. 52:1345-1354.

126. Nakamichi, I., et al. 2005. Keratin 8 overexpression promotes mouse Mallory body formation. J. Cell Biol. 171:931-937.

127. Harada, M., Strnad, P., Resurreccion, E.Z., Ku, N.O., and Omary, M.B. 2007. Keratin 18 overexpression but not phosphorylation or filament organization blocks mouse Mallory body formation. Hepatology. 45:88-96.

128.Bader, B.L., and Franke, W.W. 1990. Cell type-specific and efficient synthesis of human cytokeratin 19 in transgenic mice. Differentiation. 45:109-118.

129.Tamai, Y., et al. 2000. Cytokeratins 8 and 19 in the mouse placental development. J. Cell Biol. 151:563-572.

130.Hesse, M., Franz, T., Tamai, Y., Taketo, M.M., and Magin, T.M. 2000. Targeted deletion of keratins 18 and 19 leads to trophoblast fragility and early embryonic lethality. EMBO J. 19:5060-5070.

131. Hesse, M., et al. 2007. A mutation of keratin 18 within the coil $1 \mathrm{~A}$ consensus motif causes widespread keratin aggregation but cell type-restricted lethality in mice. Exp. Cell Res. 313:3127-3140. 